\title{
Sarmiento y el "caudillismo" en las ediciones del Facundo, algunas consideraciones para su abordaje
}

\author{
Hernán Fernández \\ hernan.fernan86@gmail.com
}

\section{Resumen}

Las diferentes investigaciones sobre las ediciones del Facundo han centrado su análisis principalmente en los cambios que Sarmiento concretó entre la primera y segunda edición al quitar los capítulos finales. Algunos mencionan la incorporación de "El General Fray Félix Aldao, gobernador de Mendoza" (1845) y "El Chacho, último caudillos de la montonera de los llanos" (1866), pero no concretan un estudio sobre los contenidos de los mismos. Tampoco los trabajos referidos al modo en que Sarmiento configura una visión del "caudillismo" en el Facundo han tomado como referencia a la vida de Aldao y vida del Chacho, desvinculando de esa manera dichas obras con el resto del escrito, marginando consecuentemente los aportes que ambas biografías podrían hacer sobre la problemática en cuestión. En base a esas falencias se busca entonces realizar un repaso por la literatura atingente a las ediciones y a los estudios sobre la configuración del "caudillismo" por Sarmiento en el Facundo. La finalidad es proponer una lectura donde se tengan presente las variaciones significativas de la obra, sobre todo en el tratamiento del fenómeno "caudillismo", en base a los cambios que provocan la anexión de vida de Aldao y vida del Chacho.

Palabras clave: variaciones - biografías - política - estudio de conteidos.

\begin{abstract}
Different researches about Facundo's editions have focused mainly on the analysis of the changes which Sarmiento performed between the first and the second edition by removing the final chapters. Some of them mention the addition of "El General Fray Felix Aldao, gobernador de Mendoza" (1845) and "El Chacho, ultimo caudillo de la montonera de los llanos" (1866), but they don't materialize a study about the contents of them. Neither the Works referred to the way in which Sarmiento sets a visión of "wardorlism" in Facundo, have taken as a reference Aldao and Chacho's life, decoupling on this way those Works with the rest of the text, consequently marginalizing the contributions that both biographies could do about the problem in question. Based on these sortcomings, it is searched to make a review of the atingente literatura of the editions and the researches about the configuration of "warlordism" by Sarmiento in Facundo. The aim is to propose a reading where significant variations of the work, especially in the treatment of "warlordism" phenomenon, based on the changes that cause the annexation of Aldao and Chacho's life, are present.
\end{abstract}

Key Words: variations - biographies - politics - study about the contents

\section{Introducción}

De vieja data son las reflexiones sobre las modificaciones que Sarmiento concretó sobre su Facundo, algunas centran su atención en las motivaciones políticas que llevaron a modificar la versión primigenia del texto (desde el folletín a los libros), otros se inmiscuyen en las necesidades literarias del autor, cualquiera sea el caso, resultan más fructíferas las visiones que no marginan ninguna de las dos posibilidades. Al ser tomado desde el plano historiográfico, un tema trabajado recurrentemente es la configuración del "caudillismo" en la 
obra, el modo en que Sarmiento entretejió una trama para poder entender y mostrar a los lectores las causas y consecuencias de ese tema que a sus ojos era el gran drama de la política pos independencia.

Alberto Palcos inició una tradición de lectura enfocada en estudiar las variaciones del Facundo en sus diversas ediciones. El autor apuntó a valorar los dotes literarios de la obra, con tal fin trabajó como base para su estudio a las intenciones políticas y literarias que llevaron a Sarmiento a publicar y luego reeditar su escrito pero con determinadas modificaciones. A la hora de analizar las variaciones se centró fundamentalmente en la supresión de los capítulos finales ("Gobierno unitario" y "Presente y porvenir"), dejando así planteado que los cambios sustanciales en las ediciones venideras estaban referidos a esta decisión, que respondía siempre a motivos políticos. Señala enfáticamente que la obra más que nada fue apreciada en la faceta política, dejando de lado la riqueza literaria, siendo según su óptica un texto perteneciente a este último campo.

Los estudios historiográficos continuaron con las premisas seńaladas por Palcos, acentuaban en el carácter político de la obra y en que las modificaciones sobre la última parte eran las sustanciales. Al estudiar el modo en que Sarmiento trabajó al "caudillismo" tuvieron en cuenta esos postulados. Todos concuerdan que el Facundo es la referencia ineludible a la hora de analizar la temática "caudillos" y el sistema de gobierno que instalaron, el "caudillismo". Sarmiento habría descrito el fenómeno en el cuerpo de su trabajo y en los últimos capítulos (que sacaría luego) colocaría la solución. Si decidió luego censurar esa última parte fue siguiendo intencionalidades atingentes a las necesidades coyunturales.

La fórmula para inmiscuirse en el Facundo partiría de considerarlo un texto político donde se aborda como tema central a la problemática del "caudillismo", las sucesivas ediciones que concreta Sarmiento persiguen finalidades políticas y por ello poseen cambios que responden a la coyuntura de publicación. Existen otros textos de Sarmiento que ponen el foco sobre el "caudillismo", los mismo son "El General Fray Félix Aldao, gobernador de Mendoza" (1845) y "El Chacho, último caudillos de la montonera de los llanos" (1863). Palcos menciona la incorporación de dichas biografías a las tres ediciones que sucedieron a la primera (en libro), también Jorge Myers comenta sobre la existencia y la importancia de los mismos a la hora de entender la comprensión sarmientina sobre el "caudillismo". Sin embargo ninguno concreta una lectura profunda de los títulos apuntados. Quedaría cerrada de éste modo la posibilidad de otro tipo de lectura sobre Facundo, una que permita ver como la obra fue mutando en su significado a partir de la anexión de las biografías referidas. Entonces, en las páginas siguientes, atendiendo a los contenidos de "vida del Fraile Aldao" y "vida del Chacho", se propone abrir el abanico de comprensión sobre el Facundo y sus variaciones en los significados que potencialmente adquirirá con la nueva configuración. El Facundo es un texto político, lo compuso Sarmiento para intervenir en la escena política, el tema central es el "caudillismo"; pero el entendimiento sobre el tema no está cerrado únicamente en la figura de Quiroga, sino que es menester reparar en otros casos, como el de Aldao y el Chacho. El objetivo es ampliar las reflexiones para comprender las relecturas que Sarmiento habría concretado sobre su Facundo en las diversas ediciones al integrar "El General Fray Félix Aldao, gobernador de Mendoza" y "El Chacho, último caudillos de la montonera de los llanos".

El hecho de citar a lo largo de este trabajo a Palcos, Halperín Dongui, Terán, Altamirano, Palti, entre otros; se debe a que en sus estudio han trabajado sobre las ediciones y la configuración del "caudillismo" en el Facundo. Hacer esta aclaración resulta importante la necesidad de destacar la existencia de otra rica bibliografía que no será utilizada producto de que toman otras facetas, como la literaria (Noé Jitrik, Ricardo Piglia, Ana María Barrenechea) o la filosófica (Luis Guerrero, Arturo Roig, José Pablo Feinmann).

La propuesta es trabajar en una primera instancia la literatura referida al modo en que Sarmiento aborda el tema "caudillismo" para pasar luego a analizar los estudios sobre las ediciones del Facundo y de esta manera exponer otro modo de abordaje sobre las ediciones.

\footnotetext{
* Universidad Nacional de San Juan, Academia Nacional de Ciencias, CONICET.

${ }^{1}$ Como se verá en el transcurso del trabajo, Jorge Myers, 1998; se diferencia en estas consideraciones sobre el Facundo.
} 


\section{El “caudillismo" en el Facundo}

El tema del "caudillismo" representó para Sarmiento la gran problemática a superar para lograr la configuración de un gobierno republicano. Por ello se abocó a describir el fenómeno, para entenderlo y, de ese modo, superarlo. La imagen del "caudillismo" que presentaba Sarmiento era negativa, contenía lo contrario a un gobierno civilizado; eran los caudillos quienes daban origen y sustento a este sistema consolidado, con el triunfo de Rosas, en toda la Argentina.

Algunas de las diversas (y cuantiosas) investigaciones centradas en su estudio sobre cómo el fenómeno fue entendido en diferentes épocas remiten al Facundo como fuente principal por desarrollar en el mismo una descripción amplia del tema. Noemí Goldman y Ricardo Salvatore, al referirse a los conceptos "caudillismo" y "caudillo", manifiestan que su construcción original se haya allí, dotando de esta manera de una importancia capital al escrito ya que marcaría el inicio de la utilización del concepto desde distintos planos, tal como político y científico y grupos románticos, positivistas, liberales, nacionalistas, etcetera.): "Desde su construcción original en el Facundo de Sarmiento, la figura del caudillo ha sido apropiada y utilizada por diversos proyectos interpretativos." ${ }^{2}$ Adhiriendo a este postulado está Pablo Buchbinder, para quien la cuestión del "caudillismo" se encuentra en los orígenes de la literatura política argentina y el Facundo representa "[...] el punto de partida insoslayable a tener en cuenta en una recapitulación historiográfica de este problema". ${ }^{3}$ Si bien la obra no es de tinte historiográfico "[...] en los análisis históricos en torno a este tema fue, probablemente, uno de los principales centros de referencia." ${ }^{\prime 4}$

Las visiones citadas enuncian a un autor escribiendo, de manera individual, sobre las problemáticas de la época, en ello Maristella Svampa da un paso más cuando, sin dejar de ver la importancia de la obra, encasilla al redactor dentro de un grupo: "Sin duda, entre los representantes de la generación del '37, es Sarmiento quien realizó en el Facundo uno de los mayores intentos de conceptualización y de síntesis de las nociones de caudillo y caudillismo, conformando lo que bien puede denominarse como su imagen canónica." ${ }^{5}$ No es menor este dato a la hora de entender a quien escribe como un personaje que responde a un grupo y, como tal, posee características determinadas en su forma de comprender la realidad histórica y de escribir. Esta aclaración resulta fundamental para entrar en otro aspecto de Sarmiento y el modo de configurar una imagen del caudillismo en Facundo.

Aunque para Altamirano Sarmiento

[...] sólo conoció la estela del movimiento que había tenido su foco en Buenos Aires y sus guías intelectuales en Esteban Echeverría y Juan Bautista Alberdi, fue ajeno al fervor que los iniciadores pusieron en la polémica antiunitaria. ${ }^{6}$

Oscar Terán ${ }^{7}$ expresa que, a pesar de su distanciamiento espacial, por su formación y pensamiento, el personaje en cuestión pertenecía a la generación del '37. Terán plantea el interrogante sobre "Quién escribe" con el fin de mostrar la correspondencia de Sarmiento con el romanticismo y, en base a esto, el modo de

\footnotetext{
${ }^{2}$ Goldman, Noemí; Salvatore, Ricardo (comp.), Caudillismos rioplatenses. Nuevas miradas a un viejo problema, Buenos Aires, Eudeba, 1998, p. 8.

${ }^{3}$ Buchbinder, Pablo, "Caudillos y caudillismo: una perspectiva historiográfica", en Goldman, Noemí; Salvatore, Ricardo (comp.), Caudillismos rioplatenses. Nuevas miradas a un viejo problema, Buenos Aires, Eudeba, 1998, p. 32

${ }^{4}$ Ibidem, pp. 32-33.

${ }^{5}$ Svampa, Maristella, "La dialéctica entre lo nuevo y lo viejo: sobre los usos y nociones del caudillismo en la argentina durante el siglo XIX", en Goldman, Noemí; Salvatore, Ricardo (comp.), Caudillismos rioplatenses. Nuevas miradas a un viejo problema, Buenos Aires, Eudeba, 1998, p. 53.

${ }^{6}$ Altamirano, Carlos, "Introducción al Facundo", en Altamirano, C., Para un programa de historia intelectual, Argentina, Siglo XXI, p. 32.

${ }^{7}$ Terán, 2007.
} 
concebir y narrar la historia. Los rasgos generales de este movimiento cultural europeo eran la valorización de la imaginación a la hora de pensar y escribir, la prevalencia de los sentimientos y pasiones por sobre todas las cosas.

Terán, Altamirano, Halperín Donghi, Palti ${ }^{8}$ y otros autores, estudian al Facundo tomando como elemento clave a dicha formación intelectual. La manera de concebir la historia se denominó historicismo al razonamiento que emplearon para percibir, explicar y escribir sobre los sucesos pasados. Consideraban que la historia estaba regida por leyes que la guiaban hacia el progreso, una de esas leyes era la fricción constante producida entre dos elementos, dotándola así de un movimiento que daba como resultado una síntesis que era siempre la civilización. Todos los componentes integrantes de la historia eran propios de la civilización porque poseían la cualidad inherente de estar en permanente movimiento, propiciando así de dinamismo al trascurso histórico. Por el contrario, lo inerte, lo estanco, será ahistórico; es decir, no forma parte de la historia al no implicar cambios o, en otras palabras, avance hacia el progreso.

Buscaron rescatar lo particular de cada época y cada lugar, destacaron a los héroes o "grandes hombres" de la historia por ver en ellos la representación de una época (desde lo cultural hasta lo histórico): "[...] valorará lo auténtico, lo propio y original de cada cultura, de cada nación, en contraposición al cosmopolitismo ilustrado [...] Desplegará por ende una búsqueda de los datos primigenios de cada cultura." El fin último de todo era "[...] dotar a cada nacionalidad de un pasado épico, prestigioso, que se hunda como se dirá- en las brumas del pasado." 10 En torno a esta manera entender los hechos históricos surgen diferentes posicionamientos con respecto a si Sarmiento vio en Quiroga a un "grande hombre". Para Anderson Imbert "[...] solo los creadores lo son [...]" por ello el líder riojano quedaría excluido de la categoría, representando sólo "[...] un tipo, una figura, una manifestación que refleja pasivamente el entorno."11 La fundamentación expresada tiene como presupuesto la pertenencia de los "grandes hombres" únicamente al campo de la civilización y por ello un "bárbaro" no ingresaría en esta categoría.

Tanto Oscar Terán como Carlos Altamirano ${ }^{12}$ al momento de comunicar la filiación de Sarmiento al romanticismo alertaron sobre la no adhesión total, tanto de él como su grupo, a todos los postulados: "Hay que notar, sin embargo, que Sarmiento (como en general los románticos argentinos) acompaña a sus maestros, los románticos europeos, sólo hasta cierto punto: no busca ni descubre en el mundo rural, como ellos, la cultura del pueblo original, una cultura que se había perdido en la ciudades por obra de una civilización cosmopolita." 13

Siguiendo este postulado se entiende que tampoco Sarmiento habría seguido a sus formadores en la idea de Quiroga como "grande hombre". Palti, Altamirano y Terán ${ }^{14}$ (entre otros) expresan que sí representó a esa figura producto de ser el personaje un fiel reflejo de una época. El texto habría tomado como eje la vida de dicho "caudillo" a causa de ver Sarmiento en el mismo los rasgos típicos de los ańos siguientes a la Revolución de Mayo, Facundo Quiroga "[...] es así mismo 'el hombre de la naturaleza' y ejemplo de la categoría del "grande hombre.." 15 Para Sarmiento el "caudillismo" es el final de un proceso de degradación,

\footnotetext{
${ }^{8}$ Terán, 2007; Altamirano, 1997 y 2005, Halperín Donghi, 2004; Palti, 2009.

${ }^{9}$ Terán, Oscar, Para leer el Facundo. Civilización y barbarie, cultura de fricción, Buenos Aires. Capital Intelectual, 2007, p. 15

${ }^{10}$ Ídem.

${ }^{11}$ Anderson Imbert, Enrique, Genio y figura de Domingo F. Sarmiento, Buenos Aires, Eudeba, 1998, p. 55; citado por Palti, Elías, El momento romántico. Nación, historia y lenguajes políticos en la Argentina del siglo XIX, Buenos Aires, Eudeba, 2009, p. 59.

${ }^{12}$ Terán, 2007; Altamirano, 2005.

${ }^{13}$ Altamirano, C., “Introducción...”, Ob. Cit., p. 52.

${ }^{14}$ Terán, 2007; Altamirano, 1997 y 2005; Palti, 2009.

${ }^{15}$ Altamirano, Carlos, "El orientalismo y la idea de despotismo en el Facundo", en Altamirano, C.; Sarlo, B., Ensayos argentinos. De Sarmiento a la Vanguardia, Argentina, Ariel, 1997, p. 98.
} 
es la "[...] sistematización de un régimen de por sí anárquico."16 Quiroga era el mayor ejemplo de "caudillo" y el régimen rosista la mayor expresión del "caudillismo".

Facundo habría surgido de motivaciones políticas del autor, quien tuvo la necesidad de dotar a la Argentina de una identidad como nación y, para ello, buscó en la historia los rasgos que la hicieran distintiva. Sarmiento en esta primera edición se muestra como el intérprete, como el pensador de la nacionalidad argentina, que se embarcará en una aventura intelectual con el fin de dotar a la naciente nación de una historia que sólo puede ser entendida develando la trama de cómo Rosas llega al poder o, dicho en palabras de Terán: "¿Por qué la revolución de mayo, una revolución libertaria e independentista, desembocó en el despotismo de Juan Manuel de Rosas? El enigma está encarnado pues en la persona misma del restaurador."17

Quiroga sería el medio para llegar a entender el sistema "caudillista" encarnado en el gobierno encabezado por Rosas. Siguiendo a Buchbinder ${ }^{18}$, se puede esquematizar el modo en Sarmiento narra el fenómeno, partiendo de la dicotomía civilización-barbarie y la contraposición entre el mundo rural y el de las ciudades. La figura de Quiroga condensa al "caudillo" y es, además, la manifestación de la nación (creencias, hábitos, inquietudes). Destaca que lo peculiar en el análisis de Sarmiento consistía en la articulación del proceso del surgimiento de los "caudillos" con un análisis profundo del marco regional y social que le había dado origen. La óptica de Sarmiento privilegiaba una perspectiva en la búsqueda por develar las raíces sociales del "caudillismo" que encontraba, por otra parte, en la descomposición del tejido social posterior a las luchas por la independencia. Desde esta visión establecía la diferencia entre los actores centrales del proceso revolucionario y los "caudillos".

Esa fricción entre lo positivo y lo negativo (civilización y barbarie respectivamente) es lo que Palti ve como la forma de concebir la historia según la lógica del historicismo romántico. La confrontación es clave, de esa manera se produce el movimiento del tiempo histórico, eso sería el progreso ascendente. La civilización debe triunfar siempre, de lo contrario no habría historia; porque si venciera la barbarie (entendida como lo estanco, lo inerte) y no habría avance hacia el progreso. Entonces la gran encrucijada para Sarmiento fue develar porqué en el Río de la Plata esta lógica no se ha dado producto de que la barbarie (con Rosas) había triunfado y convertido en historia producto a que estaba en el gobierno.

Maristella Svampa no sólo ve puro choque entre ambas categorías, es decir, "[...] no siempre estos mundos se han presentado como incompatibles [...]"19, agrega que "[...] la imagen de Civilización-Barbarie se reduce a dos oposiciones básicas. En primer lugar, existe una oposición débil, que se plantea más en términos de coexistencia que de contradicción y alude explícitamente a dos estados de sociedad y de cultura, que expresan un grado de evolución desigual." ${ }^{20}$ En segundo lugar "[...] existe una oposición fuerte a partir de la cual ya no sea plantea una diferencia de grado o de evolución entre la Civilización y la Barbarie, sino una clara y radical ruptura. Dicha ruptura se torna manifiesta en tanto y en cuanto la Barbarie se presenta, no como un estado social propiamente dicho, sino sobre todo como la disolución de todo principio de sociedad. De esta manera se contraponen la ciudad y la campaña." ${ }^{21}$ Oscar Terán ${ }^{22}$ se halla en esta línea interpretativa, para él el hecho de aparecer en el título "civilización y barbarie" indica una conjunción y no una oposición. Percibe y rescata la existencia de pasajes donde aparecen entrelazados ambos mundos (el ejemplo más claro es cuando se habla de Rosas), sumando con ello ejemplos a su negativa de considerarlos como estructuras totalmente diferentes.

\footnotetext{
${ }^{16}$ Svampa, M., Ob. Cit., p. 54.

${ }^{17}$ Terán, O., Ob. Cit., p. 29.

${ }^{18}$ Buchbinder, 1998.

${ }^{19}$ Svampa, M., Ob. Cit., p. 53.

${ }^{20}$ ibidem.

${ }^{21}$ Ibidem, pp. 53-54.

${ }^{22}$ Terán, 2007.
} 
Un autor que desarrolla otro plano en la consideración del "caudillismo" es Jorge Myers, quien enfoca su análisis no sólo en el texto Facundo, su apreciación va más allá y recae en otros escritos de Sarmiento. Según Myers, el concepto "caudillismo" no es un "eje central" del Facundo y por ello "[...] opera simplemente como un tópico más en el interior de aquella constelación vertiginosa de analogías múltiples que se superponen las unas a las otras [...] Empleado en el texto del Facundo como descripción, como epíteto peyorativo, y aún como categoría de análisis, la noción de 'caudillismo' no alcanza a convertirse en un concepto 'denso' ".23 Añade, y en esto se asemeja a Svampa ${ }^{24}$, que el concepto no llega a ser totalmente peyorativo, pero sí será cargado por Sarmiento por todo lo negativo (ignorancia, violencia, superstición.). Myers logra ir más allá del Facundo y dar luz sobre otros textos de Sarmiento "[...] que en su utilización del término aproximan desarrollos posteriores." ${ }^{25}$ y permiten agregar elementos en la construcción de las figuras "caudillos" y "caudillismo", estos son vida de Aldao, vida del Chacho y Conflictos y armonías.

Las cavilaciones de Svampa y Myers son claves para la propuesta de este trabajo. Los postulados expresados por Svampa dan paso a la reflexión sobre el modo en que Sarmiento en la vida de Aldao y vida del Chacho también describió el mundo bárbaro y el civilizado (no con tanta precisión y holgura como en Facundo). Exponiendo en los mismos también el permanente choque entre ambos estilos de vida y, a su vez, el contacto y la penetración de lo bárbaro en lo civilizado y viceversa. Fructíferos resultan los postulados de Myers al atravesar el Facundo y ver otros textos que son capitales para entender más cabalmente la conceptualización que Sarmiento creó sobre el tema "caudillismo". En esto el autor otorga una lectura más abarcativa sobre la configuración del fenómeno, sumando para su mayor entendimiento las biografías referidas a otros personajes integrantes del fenómeno "caudillismo": un Fraile apóstata y un General de la nación montonero.

Tomando estas últimas conclusiones, marcamos entonces la presencia subyacente en los diferentes estudios, tanto sobre el Facundo y en el modo de trabajar en el texto a la temática del "caudillismo", de una carencia de lectura en conjunto de las obras complementarias que hacen a las diferentes ediciones. Es menester concretar una nueva entrada donde se permita entender el cambio del significado del Facundo al ser leído en conjunto con la vida de Aldao y vida del Chacho. De esa manera se podrán comprender las relecturas que el mismo Sarmiento hizo a lo largo de los años de su principal escrito. Analizaremos a continuación como las investigaciones sobre las ediciones han trabajado la incorporación de las biografías sobre el fraile Aldao y el Chacho Peñaloza al Facundo.

\section{Las ediciones}

Explayarse sobre las ediciones del Facundo requiere ineludiblemente la referencia a Alberto Palcos por ser quien inició la tradición de estudios sobre esta temática. Si bien, en la obra "Facundo, rasgos de Sarmiento" (1934), su aporte lo concreta desde el campo de las letras, en el desarrollo de su investigación destacó la coyuntura política y su incidencia en los cambios concretados por Sarmiento en cada edición. Despliega Palcos un profundo examen sobre la obra, inmiscuyéndose en las causas políticas que impulsaron a Sarmiento a escribir la primera edición y luego concretar tres reediciones con características particulares. Con respecto a la composición, menciona la quita de los capítulos finales "Gobierno unitario" y "Presente y porvenir", acentuando en la finalidad política de esta decisión. También refiere a la anexión de dos obras biográficas más: "El General Fray Félix Aldao, gobernador de Mendoza" y "El Chacho, último caudillo de la montonera de los llanos".

\footnotetext{
${ }^{23}$ Myers, Jorge, "Las Formas complejas del poder: la problemática del caudillismo a la luz del régimen rosista", Goldman, Noemí; Salvatore, Ricardo (comp.), Caudillismos rioplatenses. Nuevas miradas a un viejo problema, Buenos Aires, Eudeba, 1998, p. 83.

${ }^{24}$ Svampa, 1998.

${ }^{25}$ Myers, J., Ob. Cit., p. 84.
} 
Además destaca la importancia de las coyunturas atingentes a cada una de las publicaciones: primera edición en 1845 (afianzamiento de Rosas en el poder), segunda en 1851 (comienzo de la campańa de Urquiza para derrocar a Rosas), tercera en 1868 (candidatura presidencial de Sarmiento) y cuarta, y última, en 1874 (finalización de su mandato como presidente). En todas prevalece la principal preocupación del sanjuanino, lograr la gobernabilidad en un país flagelado por el "caudillismo". Atendiendo a los cambios de estructura en las diferentes ediciones se advierte en la segunda la extirpación de los capítulos finales ("Gobierno unitario" y "Presente y porvenir") presentes en la primera edición (en libro) y agrega la biografía titulada "El General Fray Félix Aldao, gobernador de Mendoza". La tercera edición de 1868 contiene una novedad respecto a la segunda con la incorporación de "El Chacho, último caudillo de la montonera de los llanos”. En 1874 aparece la cuarta y más completa edición, en esta oportunidad los capítulos suprimidos son incorporados nuevamente junto a las biografías mencionadas.

Sobre todo Palcos destina la mayoría de las páginas a tratar las modificaciones de tipo textuales, siguiendo ese fin analiza los cambios en la redacción introducidos en la segunda edición (1851) en contraste con las "notas" remitidas por Alsina. La finalidad es rescatar la faceta de escritor de Sarmiento, porque percibe que sólo siguió a dichas recomendaciones en las correcciones que aludían a datos (sobre fechas, estadísticas, etc.) y en las que atendían la redacción, por ello expresa que Alsina "[...] cometió el error de criticar con espíritu de cronista un recio monumento literario." ${ }^{26}$ A pesar de las diferentes líneas destinada a reforzar esta última afirmación, Palcos no deja de poner el foco en las motivaciones políticas del autor.

Sarmiento habría cercenado en la segunda edición la obra atendiendo a las necesidades del momento, los capítulos finales podían despertar susceptibilidades entre las personas que se necesitaban en 1851 para dar por tierra de una vez por todas al sistema rosista. Además, si Sarmiento ya pensaba en ser representante de la futura república, debía evitar abordar tajantemente temas tan complejos como los desarrollados en esas páginas (nacionalización de la aduana y capitalización de Buenos Aires). Elías Palti ${ }^{27}$ no comparte esta apreciación, según su punto de vista la decisión de quitar las partes mencionadas respondió a un interés intelectual y literario del autor, ya que no encajaba con el cuerpo de la obra; pero Carlos Altamirano brinda una idea potencialmente solucionadora de esta disyuntiva: "En fin, a medida que la unidad dejó de ser una norma, tanto como un principio por discernir en las obras, la cuestión del acuerdo interno del texto perdió interés como problema por resolver." ${ }^{28}$ Autores como Guillermo Ara y Elizabeth Garrels ${ }^{29}$ no consideran a estos capítulos como una tercera parte, los ubican dentro de la segunda. Contrariamente, son muchos los que catalogan a "Gobierno unitario" y "Presente y porvenir" como una fracción diferente, entre ellos se puede citar a Halperín Donghi, quien en el prólogo a "Campaña en el Ejército Grande" comenta "[...] la tercera parte de Facundo, en que se traza el programa de gobierno que podría sustituir con ventajas al de Rosas, se sitúa en una plano distinto de las dos primeras." 30

Al momento de concretar la tercera edición en 1868 era candidato a la presidencia de Argentina, al hallarse en los Estados Unidos ${ }^{31}$ utilizó al Facundo como su carta de presentación. La estructura es similar a la segunda, nuevamente evitaba hablar de la capitalización, en esa ocasión resultaba más oportuna que nunca la decisión ya que el partido que lo apoya era el Autonomista (contrario a la nacionalización). Palcos ${ }^{32}$ destaca que la gran novedad apareció con la incorporación de un nuevo texto, "El Chacho Peñaloza, último caudillo

\footnotetext{
${ }^{26}$ Palcos, Alberto, El Facundo. Rasgos de Sarmiento, Buenos Aires, Elevación, 2 ed., 1945, p. 74.

${ }^{27}$ Palti, 2009.

${ }^{28}$ Altamirano, C., "Introducción...", Ob. Cit., p. 39.

${ }^{29}$ ARA, Guillermo: "Las ediciones del Facundo". http://revista-iberoamericana.pitt.edu; Garrels, E.: "El Facundo como folletín". http://revista-iberoamericana.pitt.edu

${ }^{30}$ Halperín Donghi, Tulio, Prólogo a Campaña en el Ejército Grande, Buenos Aires, Universidad Nacional de Quilmes, 2004, p. 20.

${ }^{31}$ Sarmiento fue Ministro Plenipotenciario en Estados Unidos, entre 1864 y 1868.

${ }^{32}$ Palcos, 1945.
} 
de las montonera de los llanos". Observa que esta última biografía estaba destinada a mostrar como Sarmiento desde la primera magistratura de San Juan ${ }^{33}$ pudo consolidar un gobierno fuerte que venció al levantamiento montonero del Chacho en 1863. También refiere a la anexión en esta tercera edición de "El general Fray Félix Aldao", observando que el mismo ya había aparecido en la segunda edición, pero sin comentar el contenido del texto. ${ }^{34}$

La cuarta edición apareció en 1874, año de finalización del mandato presidencial de Sarmiento. Esta es la última publicación efectuada por Sarmiento, posee el cuerpo de la tercera, pero ahora nuevamente se incorporan la introducción y los capítulos finales. Para $\mathrm{Palcos}^{35}$, refiriéndose a esa nueva estructuración, Sarmiento buscó poner en escena el tema de la capitalización y también dio a sus lectores un elemento clave para comparar al programa propuesto en el Facundo con su gestión.

Palcos no menciona la versión en folletín, a pesar de ser la primera en salir, todo su estudio se basa en el formato libresco. Elizabeth Garrels desarrolló un estudio donde analiza esta faceta de la obra. La autora estudió el "fenómeno del Facundo como folletín", su hipótesis es que esa versión (la primera) terminó en el capítulo "Barranca Yaco!!!" y, por ello, "Gobierno unitario" y "Presente y porvenir" no integrarían el primigenio cuerpo del trabajo. Fundamenta su argumento en que, entre otras cosas, el último número conocido de la versión en folletín no posee, como los demás, la indicación "continuará". También tiene una concepción política en cuanto al carácter de la obra. Analiza las diferencias y semejanzas con respecto al género folletinesco o, mejor expresado, "[...] como puedo haber influido en su redacción [...]"36

Otro elemento no observado por Palcos son las modificaciones de los títulos en cada publicación. Guillermo Ara brinda estos datos en un estudio donde concreta un repaso por las diferentes ediciones, incluso las producidas luego del deceso de Sarmiento. Parte de la edición en folletín, titulada "Folletín del Progreso/Facundo". La impresión de 1845 en formato de libro se denominó "CIVILIZACION I BARBARIE / Vida de /Juan Facundo Quiroga / I aspecto físico, costumbres i abitos de la REPUBLICA ARGENTINA"37, menciona que estuvo integrada por los dos capítulos ausentes en el folletín.

Con respecto a la segunda edición, el nombre cambia, en la portada se leía "VIDA DE FACUNDO QUIROGA / I aspecto fisico, costumbres y habitos de la Repiblica Argentina / seguido de / Apuntes Biogrificos / sobre el jeneral FRAI FELIZ ALDAO / por / El Autor de Arjiropolis / Segunda edicion / seguida de un exaimen critico traducido de la Revista de Ambos Mundos / Santiago / Imprenta de Julio Belin i Compania / 1851."38 Entonces Sarmiento anunciaba la incorporación de la vida de Aldao. También señala Ara que en esta oportunidad los capítulos finales son quitados junto a la introducción, refiere a motivos de carácter político y literario. No atiende al contenido de la vida de Aldao, pero si desarrolla sobre las correcciones literarias hechas en base a los apuntes de Alsina.

La tercera se tituló "FACUNDO / CIVILIZACION I BARBARIE / EN /LAS PAMPAS ARJENTINAS" ${ }^{\prime 3}$, Ara sigue a Palcos en la explicación sobre la quita de los capítulos finales, los motivos de la publicación y, también, al momento de señalar la anexión de la vida de Aldao y vida del Chacho. En cuanto a la cuarta edición, "FACUNDO / O / CIVILIZACION I BARBARIE/EN LAS PAMPAS ARGENTINAS”“40, continúa en la línea de Palcos para explicar la intencionalidad de la misma, además

\footnotetext{
${ }^{33}$ Sarmiento fue gobernador de San Juan entre 1862 y 1864, renunció y asumió la representación argentina en Estados Unidos.

${ }^{34}$ En otro escrito, titulado "Sarmiento. La vida, la obra, el genio" (1938), Palcos sí se explayará de manera escueta sobre el contenido de "Vida de Aldao".

${ }^{35}$ Palcos, 1945.

${ }^{36}$ Garrels, E.: “El Facundo como folletín”, p. 436. http://revista-iberoamericana.pitt.edu

${ }^{37}$ ARA, Guillermo: "Las ediciones del Facundo", p. 378. http://revista-iberoamericana.pitt.edu

${ }^{38}$ Ibidem, p. 380.

${ }^{39}$ Ara, G., Ob. Cit., p. 385.

${ }^{40}$ Ibidem, p. 387.
} 
menciona la restitución de las partes. Además menciona las traducciones del Facundo al francés (1853) y al inglés (1868). En cuanto a la versión francesa, sostiene que posee la misma estructura que la segunda edición, sólo que contiene la introducción. En cuanto a la tirada en inglés, fue hecha en Estados Unidos en 1868, afirma "El libro incluyó pues el apéndice antológico de gran interés ("Biographical Sketch") y el Aldao en un grueso volumen de 396 páginas." ${ }^{\text {41 }}$ Esta es la única referencia concretada por Ara sobre esta edición, no menciona nada sobre los últimos capítulos y la introducción.

Por último se puede mencionar otro trabajo referido a las ediciones, el mismo es de Mónica Scarano: "El libro y su autor: las mutaciones textuales del Facundo". Como el título lo indica, este trabajo apunta a estudiar al Sarmiento escritor: "[...] nuestra lectura se detendrá en un detalle textual preciso, de orden filológico [...]”² Concibe el carácter político de la obra y, también, acentúa en el interés literario del autor. Sigue a Palcos en la explicación sobre las motivaciones de las distintas ediciones y de sus respectivas modificaciones. Se diferencia en no mencionar la incorporación de las biografías sobre Aldao y Peñaloza en ninguna de las ediciones sucesivas, solo cita algunas modificaciones de tipo textual.

En el trabajo de Guillermo Ara se puede advertir como los títulos varían en cada edición, no repitiéndose ninguno, de esta manera se puede apreciar como los cambios en la estructura de la obra van acompañados por modificaciones en la titulación. Pero, vale advertir, ninguna de las investigaciones mencionadas ha trabajado los contenidos de las diversas ediciones. Palcos solo cita los títulos que acompańan a la segunda, tercera y cuarta, pero no concreta un análisis cabal sobre el modo en que Sarmiento retoma y relee la problemática del "caudillismo" con las biografías anexadas. El trabajo de Palcos al ser propio de las letras no profundizó en esa problemática histórica, aun así no deja de representar un aporte esencial al momento de estudiar las ediciones. Esto se ve reflejado en la referencia que los distintos autores citados en este escrito, sea en la primera o segunda parte, hacen a su obra.

\section{Consideraciones finales}

La literatura que se ocupó del Facundo lo señaló como el escrito que marcó el inicio de la configuración conceptual del "caudillismo", pero no advirtió que la obra con las modificaciones aplicadas por su autor dejó de ser sólo la vida de Quiroga y pasó a estar integrada por dos biografías más, vida de Aldao y vida del Chacho, que representaron nuevas interpretaciones. Como bien señaló Myers, hay que atender a otros textos para captar con mayor profundidad la imagen hilvanada por Sarmiento sobre el "caudillismo". Lo que sugerimos entonces es continuar esa línea para entender al Facundo como un texto integrado no sólo por la vida de Quiroga, sino por las distintas biografías que Sarmiento anexó en las sucesivas ediciones. La clave de lectura propuesta la encontramos en Palcos quien, en los primeros párrafos de El Facundo. Rasgos de Sarmiento, expresó:

[...] algunos investigadores a fuerza de contemplar exclusivamente ínfimos detalles, pierden la visión armónica del conjunto como una unidad viva, cuya belleza, diríase, se deslíe y esfuma en tediosas operaciones mecánicas (...) Aquellos pesados menesteres eruditos se detienen en la periferia de la obra: no arrojan luz sobre el pensamiento o la emoción que la anima. Analizar la gestación o escondida embriogenia de un libro, seguirlo a través de sus distintas ediciones, es tarea bien distinta. Destaca rasgos profundos, de otro modo inadvertibles. Coadyuva a desentrañar el misterio de su grandeza. ${ }^{43}$

\footnotetext{
41 Ibidem, p. 393.

${ }^{42}$ Scarano, Mónica, "El libro y su autor: las mutaciones textuales del Facundo", p. 53. http://fh.mdp.edu.ar

${ }^{43}$ Palcos, Ob. Cit., p. 10.
} 
Es en este marco interpretativo donde estudiamos a las ediciones del Facundo y la conceptualización del "caudillismo": al tomar el conjunto de las biografías como un todo, vinculándolas íntegramente, propusimos comprenderlas en su amplitud y, de esa manera, develar las relecturas hechas por Sarmiento al conjugar dichos textos. En base a esta referencia intentamos completar las lecturas desarrolladas sobre el Facundo al analizar qué quiso decir Sarmiento cuando decidió colocar la vida de Aldao y la vida del Chacho, entendiendo que las significaciones de las ediciones varían producto de las modificaciones. Nuestra perspectiva partió de la premisa de que no se puede comprender al Facundo leyendo por separado la vida de Quiroga, de Alado y el Chacho; y si esto es así es porque Sarmiento intencionalmente trastocó en diversas oportunidades la estructura de la obra con la finalidad de cambiar su mensaje.

\section{Bibliografía}

- Altamirano, C. (1997): "El orientalismo y la idea de despotismo en el Facundo", en Altamirano, C.; Sarlo, B., Ensayos argentinos. De Sarmiento a la Vanguardia, Argentina, Ariel, pp. 83 a 102.

(2005): "Introducción al Facundo", en Altamirano, C., Para un programa de historia intelectual, Argentina, Siglo XXI, pp. 25 a 61.

- Anderson Imbert, E., (1988): Genio y figura de Domingo F. Sarmiento, Buenos Aires, Eudeba.

— Ara, G.: "Las ediciones del Facundo", pp. 375 a 394. http://revista-iberoamericana.pitt.edu

- Buchbinder, P. (1998): "Caudillos y caudillismo: una perspectiva historiográfica”, Goldman, Noemí; Salvatore, Ricardo (comp.), Caudillismos rioplatenses. Nuevas miradas a un viejo problema, Buenos Aires, Eudeba, pp. 31 a 50.

— Garrels, E.: "El Facundo como folletín”, pp. 419 a 447. http://revista-iberoamericana.pitt.edu

- Goldman, N., Salvatore, R., (comp.) (1998): Caudillismos rioplatenses. Nuevas miradas a un viejo problema, Buenos Aires, Eudeba.

- Halperín Donghi, T. (2004): Prólogo a Campaña en el Ejército Grande, Buenos Aires, Universidad Nacional de Quilmes, pp. 9 a 53.

- Myers, J. (1998): "Las Formas complejas del poder: la problemática del caudillismo a la luz del régimen rosista", en Goldman, Noemí; Salvatore, Ricardo (comp.), Caudillismos rioplatenses. Nuevas miradas a un viejo problema, Buenos Aires, Eudeba, 1998, pp. 83 a 100.

- Palcos, A. (1938): Sarmiento. La vida, la obra, el genio, Buenos Aires, El Ateneo.

(1945): El Facundo. Rasgos de Sarmiento, Buenos Aires, Elevación, $2^{\circ}$ ed.

— Palti, E., (2009): El momento romántico. Nación, historia y lenguajes políticos en la Argentina del siglo XIX, Buenos Aires, Eudeba.

- Sarmiento, D.F., Civilización y barbarie. Vida de Juan Facundo Quiroga y aspecto físico, costumbres y hábitos de la República Argentina, Chile, Imprenta del Progreso, 1845. www.proyectosarmiento.com.ar

Vida de Facundo Quiroga y aspecto físico, costumbres y hábitos de la República Argentina, $2^{\circ}$ ed., Chile, Imprenta de Julio Belin y compañía, 1851. www.proyectosarmiento.com.ar

Facundo; Civilización y Barbarie en las pampas argentinas, $3^{\circ}$ ed., Nueva York; D. Apleton y Compañía, 1868. www.proyectosarmiento.com.ar

Facundo o Civilización y Barbarie en las pampas argentinas, $4^{\circ}$ ed., París, Librería Hachette, Boulevard Saint-Germain, 1874. www.proyectosarmiento.com.ar

El general D. Fray Félix Aldao, gobernador de Mendoza, Nueva York, D. Apleton y Compañía, 1868. www.proyectosarmiento.com.ar 
El Chacho, último caudillo de la montonera de Los Llanos- episodio de 1863, Nueva York, D. Apleton y Compañía, 1868. www.proyectosarmiento.com.ar

- Scarano, M., "El libro y su autor: las mutaciones textuales del Facundo", pp. 53 a 61. http://fh.mdp.edu.ar

- Svampa, M., (1998), "La dialéctica entre lo nuevo y lo viejo: sobre los usos y nociones del caudillismo en la argentina durante el siglo XIX", en Goldman, Noemí; Salvatore, Ricardo (comp.), Caudillismos rioplatenses. Nuevas miradas a un viejo problema, Buenos Aires, Eudeba, pp. 51 a 82.

— Terán, O., (2007): Para leer el Facundo. Civilización y barbarie, cultura de fricción, Buenos Aires. Capital Intelectual. 